\title{
Analysis of Gender Differences in Chinese Family Education
}

\author{
Weifeng Li a, Yifang Qu ${ }^{\mathrm{b}}$ and Lixia Liang c, * \\ School of Jinan, Jinan University, Jinan 250022, China; \\ aliweifeng96@163.com, b1243369437@qq.com, ",c11x76@163.com
}

Keywords: Bisexualization;family education;gender difference.

\begin{abstract}
China has always attached importance to the important role of family education in children's development. There are obvious gender differences in parents' participation in education, which has its complicated systemic reasons. The bisexualization family education model is more conducive to the children's physical and mental development.
\end{abstract}

\section{Introduction}

Everyone grows up with education, which is the necessary access to develop biological popole into social beings. But family education is the beginning and the base of all education, it's also a kind of special education associated with the course of growing and even accompanied by you all the time. Since the family comes out, parents and family have undertaken unaviodable social responsibility. Parents are their child first teachers, who are the most dependent and reliant on the process of child growing and also play a guide in their way to grow up. Whether parents can effectively participate in family education and the quality of family education greatly influences on rather children than country and nation's future.

China has always been attaching importance to the significant fuction of family education for kids development, emphasizing that parents paly an irreplaceable role in family education.From gender perspective, with the development of sociaty, the change of family life, the transition of culture values and the evolution of gender awareness, parents who play a family education undertaker in different gender role is a dynamic developing process and the situation of taking part in family education presents multiple gender distinctions. In reality, what are the distinctions about gender participating in family education? Why do these distinctions come into being? And how do gender distinctions effect on family education? These questiones are not only cratical issuese in present family education filed but also urgent and important topics in academia.

\section{Gender Differences in Parental Involvement in Family Education}

Parents are heavily influenced by gender roles in their involvement in family education. In family life, as the father of a male character and the mother as a female character, there are obvious gender differences in the sense of participation, participation time, participation content, and participation methods of family education.

\subsection{Awareness of Participation.}

Gender is more active in the sense of participation in family education for children and men about sense of participation is weaker.

At present social policy and cultural concept of China still believe that the child's birth and education are primarily and chiefly the responsibility of the mother. Many person do not realize that they need to actively participate in the child's growth and fulfill their father's duties in family education. A considerable part of personal division of responsibilities between husband and wife is still clinging to traditional beliefs. The understanding of the connotation of fathers is more traditional and obsolete. They think that "mothers are more suitable for raising children", that is, educating children is the mother's duty, and the responsibility for educating children is passed on to women. Males have less initiative in educating their children, less awareness of family education and less 
involvement in taking care of and educating their children. Under the influence of family education and cultural traditions, women should consciously assume more responsibility for their children's education and regard raising their children as their primary responsibility and their awareness of participation is more proactive.

Studies have shown that many fathers do not know enough about themselves as family bearers. They spend less time with their children than they do with their mothers. A survey found that in three generations of households with the same family, the father is responsible for about $5 \% \sim 10 \%$ of the tasks in educating children, and the wife is responsible for about $70 \%$ of the tasks. In a family of three, women are almost responsible for children. The total amount of education tasks.According to another survey, $48 \%$ of fathers consider themselves to be spectators in their child's home education, and $39 \%$ of them choose The mentor provided help to the child only during certain periods, and $13 \%$ of the fathers believed that they had a model role in family education. Explain that most men do not recognize the importance of their roles and their awareness of participation in family education is weak.

\subsection{Status of Participation.}

From the perspective of the participation status of men and women in family education, women play a major role in family education and play a major role in education. They are the bearers and leaders in family education. However, men have less status and role in family education than women so that they just play the role of "subsidiary".

When people come to the world, the first person they come in contact with is their own mother. The mother is closely related to her blood. Due to her child's natural dependence on her mother, and the miniaturization and nucleus of the modern family structure, her mother's family education the role and status of China have become more prominent. Women have become the main force in family education. On the other hand, for a long time, due to the influence of the concept of "female and male"within the traditional Chinese society, fathers often played a "minor"role in the process of raising their children, even if they were affected by western industrial revolution and consciousness of women. The role of men in family education has not yet undergone a breakthrough change. In the field of family education, people often emphasize the role of women as mothers, women are taken for granted as subjects, and the role of fathers as males is neglected for a long period of time, resulting in home education being equivalent to the education of mothers.Father was gradually outside family education, but only helper or complementary in family education.

In 2001, the Beijing Women Federation, the Beijing Family Education Research Association, and the Zero Market Survey and Analysis Company jointly investigated the current status of family education for children in Beijing (0 14 years old). The results showed that the mothers in the interview accounted for the entire $70.2 \%$ of the interviewed population, women only $1 / 5$ of the respondents. Taking the results of the third survey of women social status in Tianjin in 2010 as an example, in possession of 14 million. The population of Tianjin, before the child was 3 years old, $96 \%$ of fathers rarely took care of children; 6-70\% of fathers never or rarely participated in children's daily life, tutoring children's homework and other family education activities. Also released in 2016 is the latest Chinese family. The white paper on education status shows that there are less than $20 \%$ of families with father-led education. The certain extent shows that the position of father as a male in family education needs to be improved.

\subsection{The Respect of Participant Time.}

A great number of researches indicate that gender has fairly obvious differentiation in family education participant time. The participant time of female reflects the characteristics of consistency and timelines and so on, however the characteristic of male embodies periodicity and temporary etc.

The process of family education is consistent, mothers always participate in this full process, although kids are independent, they're also unaviodablely influenced by their mother.Thus mother is also regarded as a child's lifelong teacher, full course and consistency of mother education are incomparable than any teacher. Besides, mother can respond and intervene in time for children's 
matters in life, education, psychology etc, grasp the pulse of the children at any time and also find problems to timely educate.

Compared to mother, regardless of children's life and study, the participant time of father are relatively shorter, so there is a very serious "faher's absence" situation, which appears in both urban and countryside at different degeree. As the study conducted by Sina in 2009 shows that $60.7 \%$ of 1988 interwiewees think current children are lack of father's education;as to the answer that which one takes more education responsibility in your growing, $46.9 \%$ interviewees choose the mother, merely $13.0 \%$ interviewees choose the father; other surveys also draw similar conclusions.

\subsection{The Respect of Participant Content.}

The family education content of gender to children takes on distinct difference, on the one hand reflecting the breadth of content and on the other hand embodying the type of content.

As for the breadth of participant content, female is the all-round participation but male is the selective participation.Family education merges family life together.Mothers always take good care of children's education, focusing on all respects of children's study and life. Female participates in everyday life care for the process of growing as well as education activities such as academic advising and guide children's sentimental education. Fathers present the tendency of selectively simplified indicator in family education content, duing to the lack of time and energy, they always choose the key content especially focsing on study to communicate with their children.

As for the type of participant content, mothers spend more time in taking care of children's life,they are more willing to carry out some silent activeties in such process and their communication attitude is more mild. However fathers spend more time in playing games with their children obeying rules of the game and also select some adventurous activities to interact with children,their attitude is more stouthearted. These distinctions of education content will exert different influences on children, children can gain love and security from mothers and get awareneness of regulation, learn to explore and venture, acquire the development of physique and personality.

\subsection{The Respect of Participant Way.}

The distinctions of parent's family education ways are as follows, female gives priority to direct participation but male centres on indirect participation.

Direct participation means that mother directly provide life care and accompany with children, connecting family and school together, proceeding academic advising, restricting education and planning education etc. Indirect participation presents that father mainly offer economic support to their chiledren and give encourage and emotional favor to children's mother, seldom directly participating in what mother tends to do. According to pupil family study in Shanghai, father principally centres on indirect participation in the process of family education, where fathers get the lowest score in considering connecting family and school as vital form and content of parent's participation.

\section{Analysis on the Reasons of Gender Difference in Family Education}

In the family network, there are significant gender differences in parental participation in family education. Overall, there are the characteristics of "feminization" and "motherhood" in family education. The reasons can be analyzed from the following aspects.

\subsection{Influence of Traditional Concept.}

In the traditional concept of our country, the idea of " outside the male, inside the female" is deeply rooted, although we advocate the concept of equality between men and women, but the traditional male chauvinism still affects people's gender role behavior.Men represent masculinity, women represent feminine,so the men take on the task of career struggle, and the women take on the task of housework and education. The division of gender roles affects people's behavior from the concept, and also affects parents' different thinking and behavior in the process of family education participation.

The traditional idea of "men outside the main" drives men to bear more of the core pillars of the career, rather than the main role of the family to teach child, as for men outside the family education 
has become a matter of course. The father with strong traditional gender role consciousness think accompanying the child's growth and paying attention to the child's study are the responsibilities that the wife should undertake, so that men show the characteristics of weak consciousness, low status, insufficient time, limited content, single way in the participation of family education. a certain extent, the women confined to the family by the idea of "women in the main", women behind closed doors to tidy up the house, Women did housework and educate children will be praised.Although with the arrival of era the feminist movement, modern women have walked out of the house and go to work, but the foundation of traditional ideas has been preserved, making women occupy the dominant position in family education.

\subsection{The Influence of Reality.}

Nowadays facing double pressures with current condition of city life and career structure ask female undertaking family-sustaining tasks in family, however high-intensitive and long work objectively shorten father's time to accompany family. As the competition for jobs grows and the pace of life accelerates, many males regard work as the second life, who put their time and energy out of family, what's more, they stand their ground on workplace. Males negtively overlook even positively give up the process of participating in family education, resulting that the role of father is absent on family education and they have no time to look after and communicate with their children, in addition that fathers always replace substances with the accompany and the education to children, considering that only in the way creativing good material environmnent for kids, can they shoulder the responsibility.

For another, with the life pace speeding, parents will undertake more responsibilities in morden society. Lots of family positively or negtively choose their father or mother to shoulder the responsibility of family education, owing that males prevail in job market, mothers are chosen to be the main undertakers in family education.

\subsection{The Influence of Participation Mechanism.}

Apart from the influence of traditional concept and realistic factors, guarantee mechanism lacking of perfect support mechanism for parents, especially fathers participating in family education at the level of national policy, is also one of the important reasons.

The social policy plays an important role in how men undertake family education responsibilities by the common construction of the whole society, family education replicating real social relations, the role of social policy is crucial.Some scholars have studied the social policies of the "paternal" construction in countries and regions such as Sweden, the United States, Japan and Taiwan. Through adjustment of social policies, these countries and regions actively promote the construction of new paternal power, improve father's participation in family education and the quality of participation, and promote the formation of androgynous family education mode.

At present, our country lacks the social policies to ensure that men fulfill their duties as fathers. The existing relevant social policies have basically failed to recognize that the father is one of the main identities of the adult male.For example, the "Labor Insurance Regulations" which were promulgated in 1953 began to recognize that women have the right to social security in pregnancy, childbirth and maternity leave, but will also participate in the child's birth, care, upbringing facts, responsibility and right, there has been no formal recognition of men.

Although most provinces now require men to take paid parental leave, they are all rewards for late marriage and late childbirth, rather than admitting that they are men's basic rights. And the time of male maternity leave is much lower than that of women's maternity leave.This policy of proclaiming feminization and exclusion of men has seriously damaged children's right to get parental care. It will further increase the discrimination against women in the labor market, and further solidify the ideology of feminization and motherhood in family education. 


\section{Building "Bisexualization" Family Education Mode}

Family education is a systematic project, fathers and mothers respectively play different roles in family education, and they complement each other and take part in family education. They can use their respective advantages and characteristics to educate children and establish harmonious and safe parent-child relationships to form a situation of family education.

For families, parents share the responsibility of educating their children more than one party alone. A large number of facts also prove that the single gender of the family educator will cast a shadow on the development of children's psychology and personality. Bem, a psychologist who once proposed the concept of bisexualization, believes that those who have both male and female traditional advantages are more flexible and adaptable, and are more likely to succeed. From this perspective, the dualized family education model which parents and parents both actively involved in family education is more conducive to their children's physical and mental development.

Firstly, at the government level, there is need for cooperation and support from policy. Many families have disorder in function because of their unique economic pillars and the inability to afford family expenses. Therefore, from the policy perspective, establishing family support system is probably an important factor to enhance gender participation in family education and enhancing the effectiveness of parental rearing. Relevant government departments should attach importance to parents especially the father in the family education, and actively formulate corresponding policies, special funds, training teachers, supporting facilitie. In this way, it can promote the realization of Androgyny family education mode and enhance the degree of parents' participation in family education and promote quality.

Secondly, from the social level, it is necessary to correctly play the guiding role of social public opinion. Nowadays, the evaluation of a successful man pay more attention to the career achievement, but it is not necessary for men to participate in family education. Under such a social orientation, the father faded out of the family education and formed a situation of non-participation or active participation. Therefore, we should make use of the mass media and network resources to publicize the importance of father's participation in family education and improve the enthusiasm of father's participation.

\section{References}

[1]. Wei $\mathrm{Xu}$. The considering that career females break through the dilemma about family education.Chinese Adult Education.Vol. 04(2014), p.64-65.

[2]. Yanan Wang,Chao Wul. The current survey research about the degree that father participates in child family education.Labour Security World.Vol.06 (2016), 73-74.

[3]. Xinchun $\mathrm{Wu}$. The function of father is obvious in social change: the analysis based on ecological system theory.Journal of South China Normal University, Vol. 06 (2012), p.56-62.

[4]. Xiangxian Wang. Social reproduction in the urgent revolution of family----an example of the third women's social status survey in Tianjin. Journal of Shanxi Teacher's University.Vol.03 (2013), p.121-125.

[5]. Qingfang $\mathrm{Yu}$. The current survey about the father of pupil taking part in family education.Shanghai Research on Education.Vol.01 (2016), p.53-56.

[6]. Xiangxian Wang. The review concerning that Europe and America establish new duties of fateher. Journal of Jingyang. Vol.03 (2014), p.71-81.

[7]. Xiangxian Wang. How social policy bulid the dutied of father----the comparision among Sweden America and China. Collection of Women's Studies. Vol.03 (2014), p.49-54. 
[8]. Mingling $\mathrm{Xu}$. The form and research dynamics that Japanese males take part in family education.Journal of Kaifeng Education.Vol03 (2014), p.251-252.

[9]. Bofeng Song. Study on the role of father in Taiwan.Childhood Education.Vol. 03(2015), p.61. 